\title{
E-applications for Managing Trans- Logistics Activities in Sugar Supply Chain in North India
}

Rupesh Kumar, University of Petroleum and Energy Studies (UPES), Dehradun, India

\begin{abstract}
This study identifies various issues in managing transportation logistics activities on the basis of literature review and expert panel discussions so that the facilitation of e-applications can be used for managing transportation logistics activities. A field survey was conducted for checking the relevance level on a five-point Likert scale. A total of 198 responses were obtained from taken from mill managers, distributors, IT companies and large-size sugar consuming companies (LSSCC) to check the scope of e-applications for the issues in both structured and unstructured ways. With these respondents, the suitability of e-applications was checked for the issues related to transportation management activities. The study results are statistically significant and correlated to each other which help in facilitating e-applications. The study also provides some suggestive e-solutions with respect to different transportation logistics management activities with certain implications.
\end{abstract}

\section{KEYWORDS}

CART, E-Applications, GIS, GPS, LIS, Regression Method, RFID, Sugar Mills, Supply Chain, Transportation Logistics

\section{INTRODUCTION}

The Indian sugar industry, from cradle to gate, transportation logistics plays an essential role throughout the supply chain system. Figure 1 presents a simple supply chain of the sugar industry in which the basic raw material for sugar production, i.e. sugarcane comes from farmers which sell it to the millers for producing sugar and ends at the consumers for using sugar in a variety of ways (Amu et al., 2013; Kadwa and Bezuidenhout, 2015; Kumar et al., 2015). Nowadays, the material flow in the sugar supply chain becomes complex by including various by-products from the cogeneration plant and chemical plant within the sugar mills as shown in Figure 2. This Figure shows that the farmers perform various farming activities like harvesting, irrigating, plowing and cultivating for producing and further transporting sugarcane to the sugar mills through two main routes allotted by the State Government - Gate Region and Centre Region. Government agencies also support sugarcane farming activities and provide knowledge through their 24x7 call centers in several states of India (as observed during the primary survey from sugar mills in Uttar Pradesh and Uttarakhand). Figure 2 shows that the sugar mills produce sugar from cane in four stages. These consists of, receiving of cane from farmers, crushing the cane, processing for sugar production, and finally packaging of sugar according 
Figure 1. Supply chain system of sugar industry

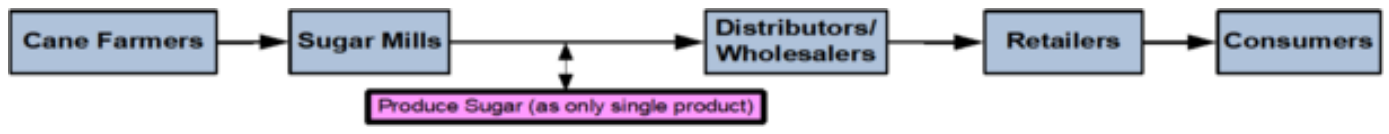

Figure 2. Material flows in supply chain system of sugar industry (Kumar et al., 2012)

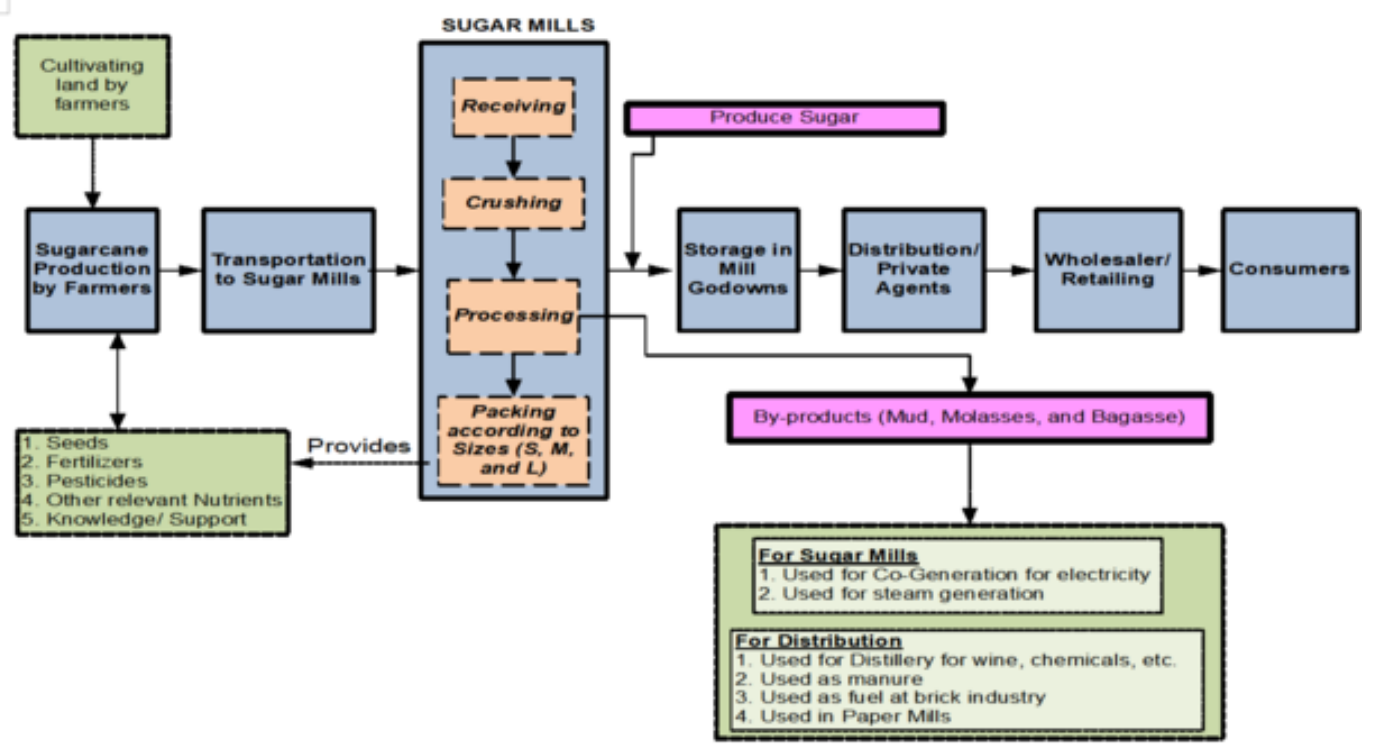

to their sizes i.e. Small, Medium and Large. The packaged sugar is stored in their mill godowns and then distributed to the wholesalers, brokers, or private agents. The wholesalers store the ordered sugar for further distribution in their area retailers and finally sell to the consumers, as shown in Figure 2. From these stages, it can be easily observed that without transportation logistics services it is tough to link all these activities together. Thus, transportation and logistics services are essential for better and smooth process in the supply chain system of the sugar industry. When the sugarcane season starts, the millers issue two types of passes i.e. one for Gate and other for Centres. These passes are allotted to the farmers' for supplying their cane to the respective mills. The whole process of supplying cane can be operated either by centers (operated by mills) or by farmers to sugar mills throughout the season by different modes of transportation such as trucks, tractors, bullock carts, etc. In India, during the crushing season, the high level of traffics on road due to improper management of transportation modes can be easily seen. The public faces severe difficulty while traveling by road. Government and other higher authorities like mill managers are trying to resolve such problematic situation by distributing slips to respective suppliers i.e. farmers with allotted time. But still, the problem exists due to limited usage of e-applications, less awareness, traditional mindset, etc., which restricts the suppliers to adopt and follow it faithfully.

In developing Asian countries, sugar is a big industry, but they also have similar issues. In a study conducted by Khushk et al. (2011), they have explored the structure of sugar cane industry in Pakistan. The Pakistani sugar industry is also very similar to Indian Sugar sector. Khushk et al. (2011) have highlighted that Pakistani sugar industry also face issues such as high cost of transportation, insufficient cane available in the mill's periphery, outdated sugar production technology. Such issues are also common to the Indian sugar industry. Li and Yang (2015) have mentioned that the Chinese 
sugar industry is the third largest in the world behind Brazil and India, but the Sugar sector in China also has many issues, some of them can be addressed by mechanization of the sugarcane production process. In a study conducted by Sukyai et al. (2016) it is reported that Thailand's sugar industry is under immense pressure to meet the food and non-food demands in the region. Toharisman and Triantarti (2016) in the context of Indonesian sugar industry have reported that currently the sugar industry in Indonesia is under stress due to lack of adequate R\&D and loss of technical efficiency.

Therefore, a high-end collaborative planning is required from both sides i.e. sugar industries and Governments. As India is the second largest producer of sugar and mostly population depends on agriculture sector but lacks behind with the up gradation and proper utilization of real-time technology due to machine cost, labor cost, traditional mindset of the transporter, limited infrastructure, etc. This makes the bottom end of supply chain moves at back foot of managing their transportation logistics activities using e-applications. Most of the sugar mills are using e-applications for their departmental activities, which are managed by their IT department. Hence, it is necessary to improve the transportation logistics services by suitable IT tools and techniques.

\section{OBJECTIVE}

The main purpose of the present study is to facilitate the use of e-applications for managing the transportation logistics activities on the basis of identified issues in the supply chain system of the sugar industry. Following are the precise objectives of the study:

- To identify relevant issues to manage transportation logistics activities;

- To analyse the identified issues with suitable analytical methods;

- To propose certain e-solutions to these issues for transportation management.

The paper is organized as follows. The first part focuses on the identification of relevant issues at the procurement and the sugar production levels via primary data collection from the expert panel (mill managers) and through secondary sources. The second part focuses on the analytical methods applied for framing a model to facilitate e-Applications for the identified issues at the transportation level. Linear regression and CART (Regression Tree) has been used to develop a relationship between the identified issues and the suitability of solving these issues with IT/e-applications. Thirdly, suitable IT solutions are suggested for dealing with the issues, which may provide optimum profits for the involved actors. To conclude, the conclusions and limitations of the present study follow.

\section{LITERATURE REVIEW}

Agro-food product supply chain suffers a lot because of poor infrastructure. Poor infrastructure includes lack of proper all-weather highway/ roads. Studies such as one conducted by Masood et al. (2011), in the context of Pakistan also highlight that such issues negatively affect supply chains in developing nations. In addition, there are inadequate cold storage facilities, transportation facilities using refrigerator vans etc. Studies conducted in the past by Salin and Nayga (2002); Rabo India Finance (2005); Joshi et al. (2009); Mishra (2010); and Singh (n.d.) have termed this infrastructure as a cold chain (cold storage facilities, transportation facilities using refrigerator vans, etc.). In India, there is an almost complete absence of cold chain infrastructure, and this result in a lot of wastage and thus, the farmers and intermediary are not able to reach potential markets and command premium prices for their produce. A study undertaken by Transport Corporation of India, Hindu (2007) and Misra et al. (2011) have given a detailed description of poor infrastructure in India. In their study, it was mentioned that a typical truck was stopped 49 times on its journey from Kolkata to Delhi i.e. 2,400 $\mathrm{km}$ in distance due to the presence of many tollgates (billing system for roads), bad road condition, 
and corrupt officers on the state borders, which lead to delays in the journey. It is common for the industrial areas to suffer because of poor roadway connections, insufficient water supply and frequent power outages due to restricted infrastructure support. Rao (2007) has identified several issues such as long and discontinuous supply chain, inadequate policy support, limited infrastructure for storage, transportation and marketing of agricultural produce, limited opportunities for value addition, and inefficient information and knowledge flows for poor agricultural development in India. These issues (if solved) offer a great amount of opportunity for raising rural incomes and ensuring sustainable development of agriculture in India with the help of e-application in agricultural activities. Such issues are common with agro supply chains the world over. Perdana (2012) in the context of Indonesia has mentioned that agro supply chains there suffer from many problems such as large product price diversity, long marketing chain, non-proportional profit margins, quality and assurance of product availability, distribution and inventory uncertainty etc.

Use of IT/ e-applications for better supply chain management has been explored in the literature in the past. In a study conducted by Rahman $(2003,2004)$, it was found that most of the e-Application in the supply chain was for the management of the transportation system while production scheduling had the least application. Anupindi and Sivakumar (2007) have given a detailed account of how e-applications/ IT have helped farmers by quoting the case of ITC e-Chopal. ITC e-Choupal had linked local farmers to global markets. Supply Chain reengineering intervention of ITC has helped farmers of soybeans, wheat, and coffee. It helped in the improvement in logistics efficiency of a commodity supply chains. In another study conducted by Akyoo and Lazaro (2007) on the supply chain framework of spices, they have narrated some key factors about the quality of the product, transportation of goods, marketing framework, and perishability of the products. Cox and Chicksand (2005) discussed the weakness and strength of the lean administration in the agricultural supply chains system in detail. They have also shown that the increased creditability can be seen by adopting lean principles by the various retailers in the supply chain. Perdana (2012) has pointed out that use of ICT (Information Communication Technology) can be one of strategies for better management of supply chains.

In the past, various studies have talked about sugar supply chain system in context of other sugar producing nations of the world. Gaucher et al. (1998, 2003) pointed out that bottlenecks and their impact on the supply chain system of sugar industry. La Reunion has followed the associated methodology to evaluate the results regarding the mixture of changes occur in the way of transportation, shutting down the trans-loading centre of supply chain system with reference to the yield of sugarcane and transport facility as shown by Gaucher et al. (2003). When the whole supply chain system was occupied by strategic model, then the logistic chain was provided on a daily basis gets motivated resulting the left-out organization equally. Therefore, the transportation of sugarcane from the cane fields to the sugar mills through the trans-loading centre is conveyed. According to Barnes et al. (2000), the trans-loading place and levels in the sugar mill, the flow of sugarcane will be delivered equally through the logistic chain as studied and the remaining suppliers are simulated in order to work out the queue delay. The industrial simulation instrument has been used to form and simulate the flow of sugarcane, which is linked throughout a known logistic chain. Gaucher et al. (2003) has explained the structure of the logistic model of flow of sugarcane forms three types of modules namely, sugarcane growers; the trans loading centre; and sugar mill-yard. These modules are linked by the transportation facilities of sugarcane from one point to another. Some of the factors that are considered for the strategy of task groups are opening/closing time or the cutting time of trans-loading centre. With the use of logistic model with the combination of strategic model solutions for various issues can be addressed. Many impacts can be solved by using the logistic model. The supply organization can be easily restructured according to the region of the re-loading centres where their distance is modified with reference to cane field. The mills, trans-loading centres and the processing units should be well equipped. The cultivators harvest capability is matched with the altered delivery allocations.

Higgins and Muchow (2003) examined the potential benefits of alternative cane supply arrangements in the Australian sugar industry. They have measured individual sectors like integration 
of growing, harvesting, transportation, milling, and marketing of the supply chain system of sugar industry. These sectors have added significant value in the past and maintain the international competitiveness for the industry by improving its individual sectors. The authors have used operations research techniques to focus on the consequences of different sugar prices and costs; consequences of year-to-year variability; and integrating the harvest date of cane options into a wider cane supply management system.

Ioannou (2005) studied the reorganization process of supply chain of Hellenic sugar industry (HSI) in Greece. They reported that without resorting to radical restructuring of the existing logistics operations, but through optimal planning of inter-node material transfers, HSI has saved almost one million US dollars and improved demand coverage. In this study, supply chain was studied, customer demand and logistics cost were analyzed and an appropriate transportation model to derive optimal distribution practices was developed.

Everingham et al. (2002) studied uncertainty associated with variable climatic conditions for sugarcane industries. This variability produces impact across an integrated supply chain comprising of cane growing, harvesting, transportation, milling, and marketing. A comprehensive systems approach for using seasonal climate forecast system to improve risk management and decision-making capability across different sectors of sugar supply chain will improve risk management and decisionmaking capability of the entire supply chain. The e-application can be very important in developing the seasonal climate forecast systems.

Most of the studies related to the management of transportation logistics activities of sugar supply chain are done in different countries like, La Reunion, Australia, Greece, and others. The frequent usage of e-commerce/ IT in transportation management can be easily found for the other sectors like automotive, manufacturing, agriculture and many others but, rarely found in Indian sugar sector. Thus, it is imperative to investigate the scope e-applications/ IT in the Indian sugar supply chain to improve its performance. Perdana (2012) has reported that by using IT/ e-applications increases the effectiveness of the loading-unloading by $6.2 \%$, decreases material handling costs by $5.6 \%$, and improved inventory accuracy by $99.9 \%$. Thus, the use of IT/ e-applications has shown to have positive effect on the supply chains. Therefore, it becomes imperative to explore the use of IT/ e-applications in the context of Indian sugar supply chain.

Further exploration of secondary sources like, online databases (Pro-Quest, EBSCOS, Google Scholar, etc.), conferences proceedings, seminars and workshops conducted by "Confederation of Indian Industry (CII)" revealed various issues related to transportation logistics management of sugar supply chain. Therefore, following are the relevant issues for transportation management activities:

- Pickups from regions distribution centres (Pick up of raw material from the source);

- Drop offs at regional distribution centres (Delivery of raw material at the destination);

- Monitor on time arrivals of carriers (monitoring of transportation used);

- Managing claims and improving performance (Related to better handling of documentation/ formalities that are needed for transportation using IT/ e-applications);

- Hence, considering the null hypothesis.

Hypothesis 1: There is no significant relationship between relevance of transportation issues (T1, $\mathrm{T} 2$, and T3) and managing overall performance for managing transportation logistics activities using e-applications/ IT (T4).

\section{RESEARCH METHODOLOGY}

The process for data collection was done by undertaking a self-administered survey by visiting 30 sugar mills (4 responses from each mill managers totaling to 83 valid responses). 149 distributors were also visited (includes brokers, wholesalers and retailers, totaling to 52 valid responses). 60 IT companies 
were also surveyed, these IT companies consisted of only supply chain solution providers, and 60 valid responses were obtained from the IT companies. 11 Large size sugar consuming companies (total valid responses obtained were 11) in Uttar Pradesh and Uttarakhand, India for understanding the scope of e-applications for issues to manage the transportation logistics activities. Interviews were conducted in both structured and unstructured ways with these experts. The survey was conducted from April 2011 to September 2011.

The survey questionnaire was designed in English language for collecting the responses. The respondents were asked to rate the relevance of transportation related issues (Pickups from regions distribution centres, drop offs at regional distribution centres, monitor on time arrivals of carriers) on a five-point Likert scale $(1=$ Not at all relevant, $3=$ Neutral, and $5=$ Highly relevant) to check the relevance of these issues related to transportation logistics activities. The respondents were also asked to rate the scope of e-application/ IT use of solving the issue of managing claims such as documentation needed for transportation and other formalities $(1=$ Not at all relevant, $3=$ neutral, $5=$ highly relevant). Thus, the current study tries to establish the relationship between the relevance of transportation/ logistics issues and the relevance of the scope of e-applications for solving transportation issues.

\section{ANALYSIS}

The total number of valid responses obtained from sugar mills, distributors, IT companies and LSSCC is 198. Descriptive statistics showing mean and standard deviation for various issues for managing transportation logistics activities is presented in Table 1. The Pearson correlation with significant 2-tailed test is employed to test statistical significance of these issues (T1 to T4). Table 2 shows the correlation matrix for the four issues to manage transportation logistics activities. This table indicates that all are correlated (100\%) and significant at 0.01 levels. This shows that all are highly correlated to each other and have no evidence of multi-collinearity (generally 0.9 and above) (Hair et al., 1995).

\subsection{Regression Model and Hypothesis Testing}

The regression method was employed for developing a relationship between the independent and dependent variable. For transportation management activities, there are four issues sorted into two criteria i.e. dependent and independent variables. In this study, there is one dependent variable and remaining others are independent variables:

- Dependent Variable: Managing claims and improving overall performance (T4); and

- Independent Variables: Pickups from regions distribution centres (T1), Drop offs at regional distribution centres (T2), Monitor on time arrivals of carriers (T3) The working hypothesis is as follows:

Table 1. Descriptive statistics for issues to manage transportation logistics activities

\begin{tabular}{|l|l|l|l|}
\hline \multicolumn{1}{|c|}{ Notations } & \multicolumn{1}{|c|}{ Issues } & \multicolumn{1}{c|}{ Mean } & \multicolumn{1}{c|}{ S.D. } \\
\hline T1 & 1. Pickups, regions distribution centres & 4.273 & 0.6343498 \\
\hline T2 & 2. Drop offs regional distribution centres & 4.278 & 0.6361457 \\
\hline T3 & 3. Monitor on time arrivals of carriers & 4.444 & 0.5913457 \\
\hline T4 & 4. Managing claims overall performance & 4.379 & 0.5900654 \\
\hline
\end{tabular}


Table 2. Pearson correlation for issues to manage transportation logistics activities

\begin{tabular}{|l|l|l|l|l|l|}
\hline \multicolumn{1}{|c|}{ Iss. } & & \multicolumn{1}{c|}{ T1 } & \multicolumn{1}{c|}{ T2 } & \multicolumn{1}{c|}{ T3 } & \\
\hline T1 & $\begin{array}{l}\text { Pearson Corr. } \\
\text { Sig. (2-tailed) }\end{array}$ & 1 & & & \\
\hline T2 & $\begin{array}{l}\text { Pearson Corr. } \\
\text { Sig. (2-tailed) }\end{array}$ & $\begin{array}{l}.893^{* *} \\
.000\end{array}$ & 1 & & \\
\hline T3 & Pearson Corr. & $\begin{array}{l}.500^{* *} \\
.000\end{array}$ & $\begin{array}{l}.520 * * \\
.000\end{array}$ & 1 & \\
\hline \multirow{2}{*}{ T4 } & Sig. (2-tailed) & $\begin{array}{l}.407 * * \\
.000\end{array}$ & $\begin{array}{l}.562^{* *} \\
.000\end{array}$ & 1 \\
\hline
\end{tabular}

Note: ** Correlation is significant at the 0.05 level (2-tailed)

Hypothesis 1: There is no significant relationship between relevance of transportation issues (T1, $\mathrm{T} 2$, and $\mathrm{T} 3$ ) and managing overall performance for managing transportation logistics activities using e-applications/ IT (T4).

Table 2 shows the data obtained for these issues are highly correlated to each other and have no multi-collinearity among them. This indicates the suitable base for performing further analysis with the help of regression method. Table 3 shows the result of regression analysis regarding different issues indicates the coefficient $(\beta)$ values and T-test values. From this table, the following regression equation is obtained:

$\mathrm{T} 4=1.549+0.214(\mathrm{~T} 1)-0.038(\mathrm{~T} 2)+0.467(\mathrm{~T} 3)$

Table 4 indicates that the coefficient $(\beta)$ for T1, T2 and T3 are $0.2114,-0.038$ and 0.467 respectively. The T-test value for T3 coefficient is 6.863 which is significant at level of 0.000 but values for $\mathrm{T} 1$ and $\mathrm{T} 2$ are 1.774 and -0.316 has a significance level of 0.07 and 0.75 respectively, which is well above the minimum value of 0.05 for $5 \%$ significance. This means T1 and T2 are not significantly affecting T4. The F-ratio for the entire model is 34.1 (df: 3 and 194) with a strong significant level of 0.000 .

The result also shows that the $\mathrm{R}^{2}$ value of the regression model is 0.3453 , which means that that model explains $34.53 \%$ of variance in managing the overall performance (T4), with the help of predictors such as monitoring the transportation activities (T1, T2 and T3). Table 3 shows the adjusted $R^{2}$ value of 0.3351 . The difference between the $R^{2}$ value and adjusted $R^{2}$ is 0.012 i.e. $1.02 \%$ only. This means there is not much difference between these values i.e. a very good result. Thus, the results are statistically significant and related to each other, which help in promoting and managing

Table 3. Regressions results for managing claims overall performance of transportation logistics activities (t4)

\begin{tabular}{|l|l|l|l|}
\hline Issues/ Predictors/ Model & \multicolumn{1}{|c|}{ Coefficient $(\boldsymbol{\beta})$} & \multicolumn{1}{|c|}{ T-Test } & \multicolumn{1}{c|}{ Significant of T } \\
\hline Intercept & 1.54949 & 5.412 & 0.000 \\
\hline T1 & 0.21404 & 1.774 & 0.0776 \\
\hline T2 & -0.03851 & -0.316 & 0.7525 \\
\hline T3 & 0.46788 & $\mathbf{6 . 8 6 3}$ & $\mathbf{0 . 0 0 0}$ \\
\hline $\begin{array}{l}\text { Multiple R-squared: } 0.3453, \text { Adjusted R-squared: } 0.3351 \\
\text { F-statistic: 34.1 on 3 and 194 DF, p-value: } 0.000\end{array}$ \\
\hline
\end{tabular}


Table 4. e-Solutions for managing transportation logistics activities

\begin{tabular}{|c|c|c|}
\hline S. No. & Issues & IT Applications \\
\hline 1 & $\begin{array}{l}\text { - Sharing and networking the data among supply } \\
\text { chain partners }\end{array}$ & - Geographical Information Systems (GIS) \\
\hline 2 & $\begin{array}{l}\text { - Tracking and locating the exact position of loaded } \\
\text { vehicles } \\
\text { - Shortest distance to reach destination } \\
\text { - Routing } \\
\text { - Scheduling system } \\
\text { - Managing pickups and drop offs regional } \\
\text { distribution centre's } \\
\text { - Monitoring the on-time arrival of carriers }\end{array}$ & $\begin{array}{l}\text { - Global Positioning System (GPS) } \\
\text { - Automatic Vehicle Locator (AVL) } \\
\text { - Satellite routing } \\
\text { - Real Time Communication Capability } \\
\text { - SAP or ERP } \\
\text { - EDI } \\
\text { - Bar Coding } \\
\text { - Web technology using XML } \\
\text { - RFID } \\
\text { - Logistics Operation Systems (LOS) }\end{array}$ \\
\hline 3 & - Managing the flow of information & - Logistics Information Systems (LIS) \\
\hline
\end{tabular}

the transportation logistics activities by tackling these issues (T1, T2 and T3) to further improve the overall performance (T4) with the help of e-applications.

The above data was also analysed through a regression tree model (CART model). CART model provides a visual representation of the relationship between the dependent and independent variables. This makes it easy to interpret the relationships and explain the predictions to industry actors. In addition, CART can also model relationships in data when the data is non-linear. Readers can refer to James et al. (2013) for a detailed discussion on CART (regression trees). From the CART model in Figure 3, we can see that that first split happens with $\mathrm{T} 3(\mathrm{~T} 3<4.5$ yes/no\}). This indicates that $\mathrm{T} 3$ is the most important predictor of T4, i.e. T4 is most affected by T3. The first split always happens with the most important predictor (James et al., 2013). The second split happens with $\mathrm{T} 1(\mathrm{~T} 1<4.5)$, this indicates that $\mathrm{T} 1$ is the second in terms of effect on T4. Lastly, the split happens with $\mathrm{T} 2(\mathrm{~T} 2<4.5)$, this indicates that $\mathrm{T} 2$ is the affects $\mathrm{T} 4$, the least. To interpret the regression tree, we just follow the tree structure. For example, if we start at the top (i.e. the root), the first split happens with $\mathrm{T} 3(\mathrm{~T} 3<4.5$ yes/no $\})$. This means that if the value of $\mathrm{T} 3$ is less than 4.5 then proceed to the left-hand side of the tree where further spiting happens, else (NO), the predicted value of T4 will be 4.7. The box shown at the end of the first 'No' branch is called a leaf. The leaf shows that there are a total $49 \%$ of cases in the data, where the value of T3>4.5 with a predicted T4 value of 4.7. It means that when the value of T3 exceeds 4.5 , means when the T3 issue is highly relevant, then in such cases, actors should immediately implement e-applications/ IT solutions for addressing transportation and logistics issues (as the model in Figure 3 shows that, if T3>4.5, the predicted value of T4 is 4.7). The performance of the CART model was tested on the training data itself. The mean absolute error for the model is 0.311525 , the mean absolute error is the average error between the values of the dependent variable in the dataset vs the values predicted by the CART model. The mean absolute error is interpreted in relation to the scale of the independent and dependent variables. In the above case, a mean absolute error of 0.311525 indicates that there is only 0.3 error in the actual vs predicted values of T4, based on T1, T2 and T3.

Thus, from the linear regression analysis and CART model, we can conclude that e-applications are very useful for managing transportation logistics activities. T3 is the issue, which can be most effectively managed with IT/ e-applications. 


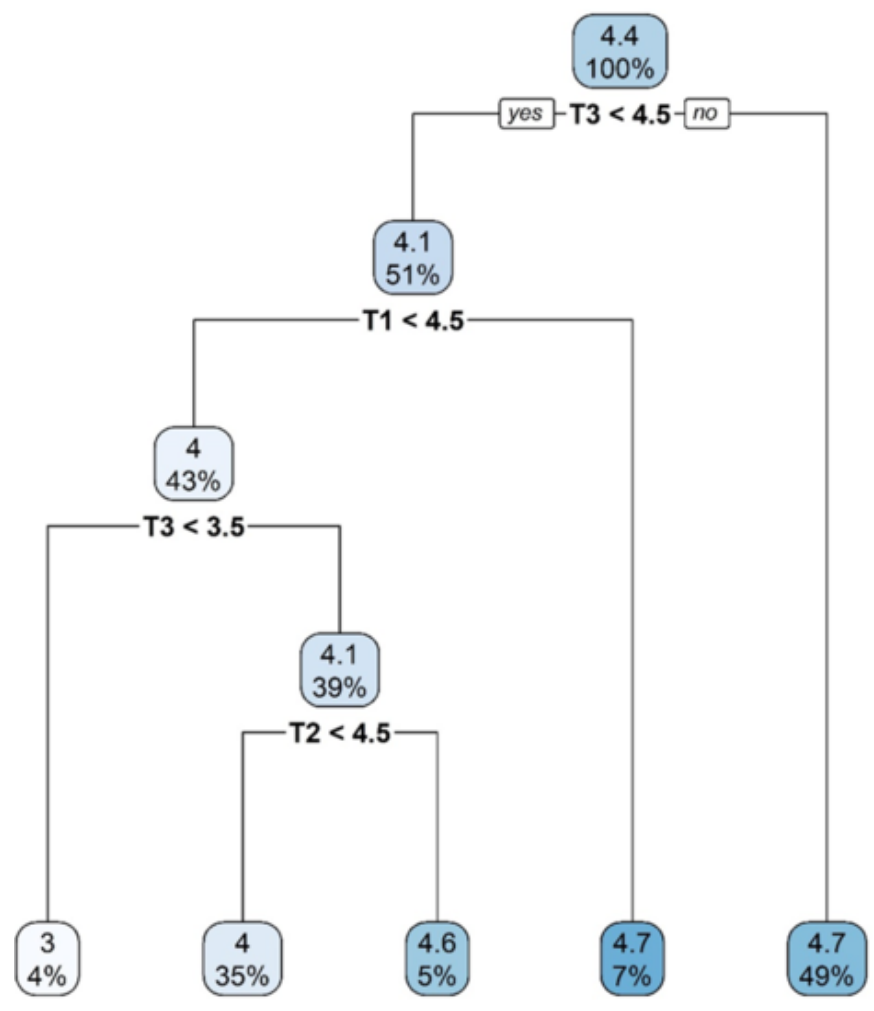

\section{DISCUSSION AND IMPLICATIONS}

The result shows that issues - namely Pickups from regions distribution centres (T1); drop offs at regional distribution centres (T2); Monitor on time arrivals of carriers (T3); and Managing claims and improving performance (T4) are developing a relationship which helps in managing the transportation logistics activities through e-applications/ IT. The results of statistical analysis indicate that there is significant relationship between issue T3 (Monitor on time arrivals of carriers) and Managing claims and improving performance (T4) for managing transportation logistics activities. The issue T3 (Monitor on time arrivals of carriers) is the most relevant issue (mean score: 4.44, Table 1). Therefore, it is necessary to provide solutions to different transportation logistics activities with the use of e-applications as mentioned below.

Geographical Information Systems (GIS) (Berry, 1999) is made up of hardware and software components, which can be used for sharing and networking the data among supply chain partners i.e. between centre's, millers, and distributors. This system helps in the transportation logistics management. Kumar and Agrawal (2011) have pointed out that in a supply chain GIS can be used to map manufacturing units, suppliers, distribution centers and routing of vehicles. They have proposed using GIS as a part of decision support for effective supply chain management. Now day's industry actors can avail the facility of Internet GIS or Web Mapping for better route planning and tracking of materials in the supply chains. Kumar and Agrawal (2011) have pointed out that GIS can be an effective tool for solving routing issues (to find the shortest path) and for finding alternative paths in case of any problem with the original shortest route. Logistics companies such as ARAMEX and DHL have already started to make use of GIS for vehicle tracking and dispatch system (Balaa, 2018). ArcGIS is one such software package that can be used for such tasks. 
Global Positioning System (GPS), Automatic Vehicle Locator (AVL), Satellite routing, and Real Time Communication Capability helps in tracking and locating the exact position of loaded vehicles, shortest distance to reach destination, routing, scheduling system, etc. These technologies helps in managing the overall performance of the transportation logistics activities such as pickups and drop offs regional distribution centers', and monitoring the on-time arrival of carriers. For doing such activity, the use of computer system is also necessary with some suitable software i.e. SAP or ERP. Thaqi (2015) has provided some cases where GIS and GPS are used as an integrated system for monitoring law enforcement vehicles, as the task of GIS is to provide mapping of locations, precise spatial information and GPS helps monitoring and tracking police officers in real time. This tactical technology can also be used in case of sugar supply chains to have a better understanding of the area through GIS and better monitoring of transport vehicles through GPS.

EDI, Bar Coding, Web technology using XML (Kumar et al., 2010), and RFID can be used for managing the transportation logistics activities (Vijayaraman \& Osyk, 2006; Attaran, 2007; Kumbhar, 2011). EDI (Electronic Data Interchange) has enhanced the communication between firms, which is essential proper supply chain management. This is done by standardizing the data formatting and transmission protocols. EDI requires firms to have common data formatting and transmission standards or protocols. Currently JAL (Japan Airlines Limited) is using EDI to manage its logistics and supply chain activities (Gurung, 2006).

Mehta (2018) have reported that use of RFID in supply chains can help to provide better tracking of inventory, which leads to reduction in cases of stock outs, increased visibility, improved collaboration with supply chain partners, efficient consignment handling, warehouse management and shorter order to cash cycles. Mehta (2018) have also listed some of the benefits of RFID over barcodes for supply chain applications such as, RFID can withstand harsh conditions, RFID tags are rewritable (can be used again), reading information from RFID is fast (several tags can be read simultaneously) and less labor intensive and lastly RFID is very secure when it comes to tampering. Walmart is already utilizing RFID technology for better supply chain management.

Logistics Information Systems (LIS) is the logistic information technology, which helps in managing the flow of information for transportation logistics management (Gurung, 2006). In this regard Perdana (2012) has provided a framework for a LIS for agro- industry specifically, this LIS is called Agricultural logistics information system. ePROMIS Transportation \& Logistics and SAP are some providers of necessary software packages for LIS.

Logistics Operation Systems (LOS) is the transactional application used for transportation purpose (Gurung, 2006). Logistics operating systems (LOS) refer to transactional applications such as order entry/ order processing, warehousing, and transportation. LOS is a sub class of LIS.

Currently, sugar mills in India have adopted IT/ e-applications at a very rudimentary level (such as spreadsheets, book keeping software packages, etc.), but they not adopted these innovative e-applications for their transportation logistics activities. Hence, it is highly recommended to adopt such for improving the overall performance of sugar supply chain. Thus, the facilitation of e-applications plays an important role in the management of transportation logistics activities.

Table 6 shows that the e-solutions help in managing different issues for transportation logistics activities. E-solutions provide benefits to the transporters or third-party logistics services in different ways in the supply chain system of the sugar industry as shown in Figure 4. Thus, the role of IT helps the transporters and 3PLs in managing their different activities. Figure 5. Shows how these IT solutions/ e-applications can be used at different stages in the transport activities.

\section{CONCLUSION, LIMITATIONS AND STUDY SCOPE}

E-applications/ IT implementation helps in managing different transportation logistics activities, which have certain implications like time management, carrier selection, traffic management, on-time delivery of products or by-products, fleet management, bringing transparency, cross 


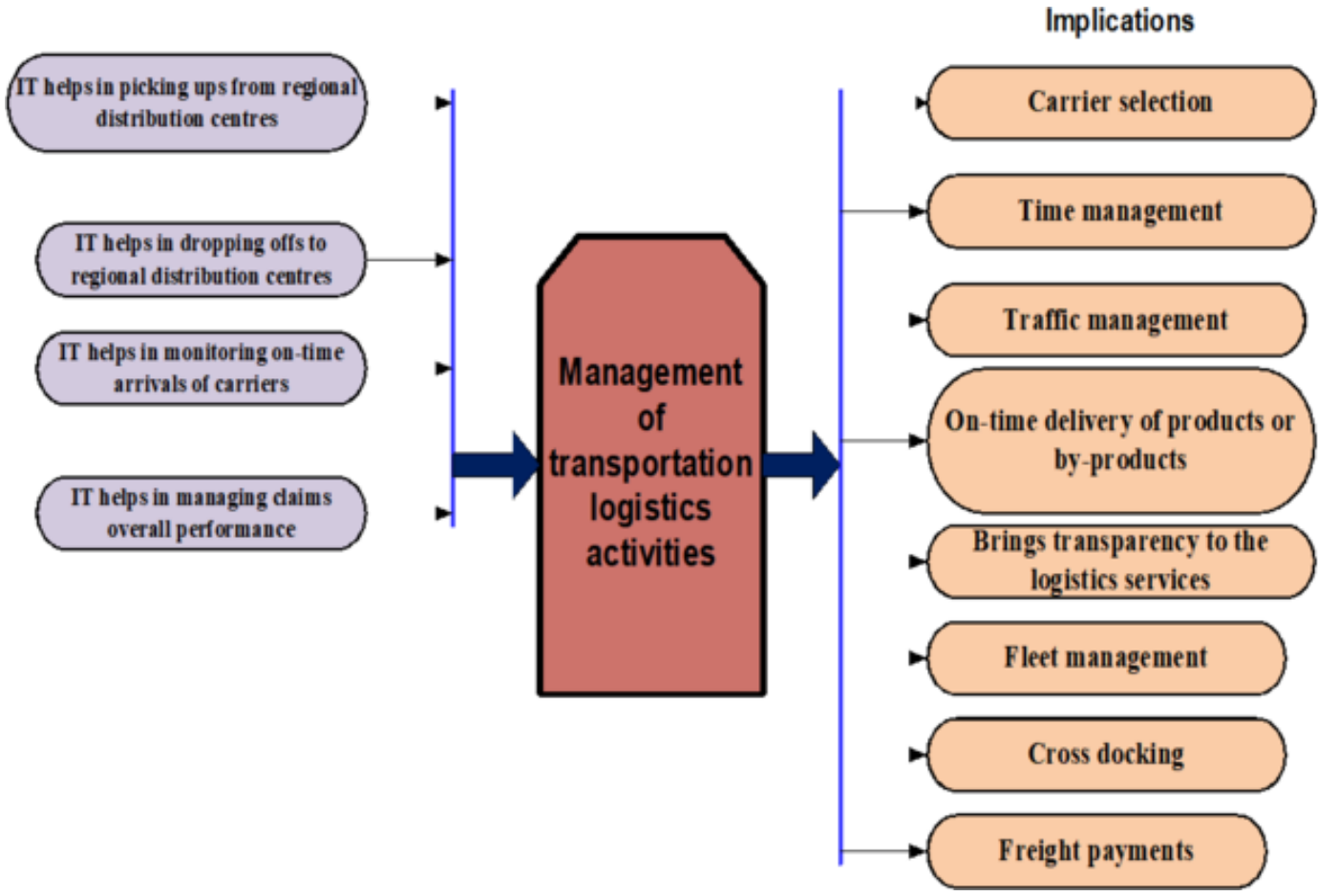

Figure 5. Use of IT solutions/ e-applications at different stages in transportation logistics activities

At the pick up at regional center

\section{Communicating necessary information} to the transporter and the receiver about the consignment

\section{Deciding route of the transport} vehicles and tracking of transport in real-time

At the drop off center

\section{Use of barcodes/ RFID to label} consignments

\section{Use of LIS/ EDI}

\section{Use of GIS/ GPS}

\section{and receive consignments}


docking, and freight payments. There is still a vast potential for adoption of latest e-solutions, which helps in managing the transportation pickups, drop-offs, monitoring and improving logistics activities. Without proper management of transportation logistics activities, the supply chain system of any industry such as sugar may directly impacts with its production and profitability. Thus, for seamless business activities, it is necessary to create a common platform of e-application.

The study scope is limited to the states of Uttar Pradesh and Uttarakhand in India. Respondents from other states in India can be targeted for future studies. Limited number of sugar mills and only Indian sugar mills were targeted to collect samples from Uttar Pradesh and Uttarakhand. The results and limitations of this study present a good starting point for exploring future work for the use of e-applications in the management of different types of activities such as vendor, inventory and distribution activities. This can be done by targeting the different supply chain partners, namely the millers, distributors and other stakeholders for collecting relevant information. Later, certain e-solutions can be proposed for managing these activities. The practical development of e-applications may bring changes to the sugar supply chain in Uttar Pradesh and beyond. In future work, e-commerce architecture (Kumar et al., 2010) can be developed by showing the usefulness of IT at different levels of sugar supply chain. This architecture may be adopted by different Government or private organizations to facilitate better communication among the supply chain partners. The sugar industry may increase its competitiveness compared to other industries by using e-applications (Kumar et al., 2013, 2014, 2015). The traditional use of business methods may be replaced with new and updated technologies, where there is a good scope for research. The study would be conducted and analyzed further by using other methods like, Fuzzy Analytical Hierarchy Process, DEA and MICMAC Analysis. 


\section{REFERENCES}

Akyoo, A., \& Lazaro, E. (2007). The spice industry in Tanzania: General profile, supply chain structure, and food standards compliance issues. DIIS. Retrieved from http://www.diis.dk/

Amu, L. G., Garcia, J. A., Galvis, D. E., \& Rubiano, O. (2013). Optimisation of harvest resources in a Columbian sugar mill by use of simulation models. Proceedings of the International Society of Sugar Cane Technologists, $28,147-154$.

Anupindi, R., \& Sivakumar, S. (2007). Supply chain reengineering in agri-business: A case study of ITC's e-Choupal. In H. L. Lee \& C.-Y. Lee (Eds.), Building supply chain excellence in emerging economies (pp. 265-307). NY: Springer; doi:10.1007/978-0-387-38429-0_12

Attaran, M. (2007). RFID: An enabler of supply chain operations. Supply Chain Management, 12(4), 249-257. doi: $10.1108 / 13598540710759763$

Balaa, A. (2018). Geographic Information Systems in the Vehicle Tracking and Dispatch Industry: An Applied Experience. Retrieved from http://www.saudigis.org/FCKFiles/File/SaudiGISArchive/3rdGIS/Papers/30_E_ AnisBalaa_Lebanon.pdf

Barnes, A. J., Meyer, E., \& Schmidt, E. (2000). Evaluation of methods to reduce harvest-to-crush delays using a simulation model. Proceedings of the South African Sugar Technologists Association, 74, 25-28.

Berry, J. K. (1999). GIS technology in environmental management: A brief history, trends and probable future. In D. L. Soden \& B. S. Steel (Eds.), Handbook of Global Environmental Policy and Administration (pp. 49-76). New York, NY: Marcel Dekker Publishers.

Burton, L. J., \& Mazerolle, S. M. (2011). Survey instrument validity part I: Principles of survey instrument development and validation in athletic training education research. Athletic Training Education Journal, 6(1), 27-35. Retrieved from http://nataej.org/

Cox, A., \& Chicksand, D. (2005). The limits of lean management thinking: Multiple retailers and food and farming supply chains. European Management Journal, 23(6), 648-662. doi:10.1016/j.emj.2005.10.010

Everingham, Y. L., Muchow, R. C., Stone, R. C., Inman-Bamber, N. G., Singels, A., \& Bezuidenhout, C. N. (2002). Enhanced risk management and decision-making capability across the sugarcane industry value chain based on seasonal climate forecasts. Agricultural Systems, 74(3), 459-477. doi:10.1016/S0308-521X(02)00050-1

Floyd, F. J., \& Widaman, K. F. (1995). Factor analysis in the development and refinement of clinical assessment instruments. Psychological Assessment, 7(3), 286-299. doi:10.1037/1040-3590.7.3.286

Gaucher, S., Le Gal, P. Y., \& Soler, G. (2003). Modelling supply chain management in the sugar industry. Proceedings of the South African Sugar Technologists Association, 7, 542-554.

Gaucher, S., Leroy, P., Soler, L.-G., \& Tanguy, H. (1998). Modelling as a support for diagnosis and negotiation in the redesign of agro-food industries supplying organisation. In G. W. Ziggers, J. H. Trienekens, \& P. J. P. Zuurbier (Eds.), Proceedings of the Third International Conference on Chain Management in Agribusiness and the Food Industry (pp. 679-689). Netherlands: Wageningen Agricultural University.

Gupta, S. L., \& Gupta, H. (2011). SPSS 17.0 for researchers. New Delhi, India: International Book House Pvt. Ltd.

Gurung, A. (2006). A survey of information technologies in logistics management. In M. Rao (Ed.), Proceedings of the 37th Annual Conference of SWDSI (pp. 618-626). Bricktown, OK: The University of Mississippi Press.

Hair, J. F., Anderson, R. E., Tatham, R. L., \& Black, W. C. (1995). Multivariate data analysis: With readings (4th ed.). New Jersey: Prentice Hall College Div.

Higgins, A. J., \& Muchow, R. C. (2003). Assessing the potential benefits of alternative cane supply arrangements in the Australian sugar industry. Agricultural Systems, 76(2), 623-638. doi:10.1016/S0308-521X(02)00031-8

Ioannou, G. (2005). Streamlining the supply chain of the Hellenic sugar industry. Journal of Food Engineering, 70(3), 323-332. doi:10.1016/j.jfoodeng.2004.01.041

James, G., Witten, D., Hastie, T., \& Tibshirani, R. (2013). An Introduction to Statistical Learning with Applications in $R$. New York: Springer. doi:10.1007/978-1-4614-7138-7 
Joshi, R., Banwet, D. K., \& Shankar, R. (2009). Indian cold chain: Modeling the inhibitors. British Food Journal, 111(11), 1260-1283. doi:10.1108/00070700911001077

Kadwa, M., \& Bezuidenhout, C. N. (2015). Modelling sugarcane supply consistency at a sugar mill. Computers and Electronics in Agriculture, 111, 107-111. doi:10.1016/j.compag.2014.12.019

Khushk, A. M., Memon, M., \& Saeed, I. (2011). Analysis of sugar industry competitiveness in Pakistan. Journal of Agricultural Research, 49(1), 137-151.

Kumar, R., Agrawal, R., \& Sharma, V. (2013). e-Applications in Indian agri-food supply chain: Relationship among enablers. Global Business Review, 14(4), 711-727. doi:10.1177/0972150913501610

Kumar, R., Agrawal, R., \& Sharma, V. (2014). Barriers to e-Application in agrifood supply chain. In J. Wang (Ed.), Encyclopedia of Business Analytics and Optimization (pp. 235-248). Hershey, PA: IGI Global. doi:10.4018/9781-4666-5202-6.ch022

Kumar, R., Agrawal, R., \& Sharma, V. (2015). IT Enablement in sugar supply chain: An approach for farmers. International Journal of Business Performance and Supply Chain Modelling, 7(4), 360-381. doi:10.1504/ IJBPSCM.2015.073770

Kumar, R., Nath, V., Agrawal, R., \& Sharma, V. (2012). Green supply chain management: A case of sugar industry in India. In Proceedings of National Conference on Emerging Challenges for Sustainable Business (ECSB 2012) (pp. 1697-1708). Roorkee, India: Indian Institute of Technology Roorkee; Retrieved from http:// domsiitr.info/allpaper.html

Kumar, R., Organero, M. M., \& Agrawal, R. (2010). XML secure documents for a secure e-commerce architecture. Global Journal of Enterprise Information System, 2(1), 35-45.

Kumar, S., \& Agrawal, S. (2011). GIS as a decision support for supply chain management. Geospatial World Forum.

Kumbhar, R. D. (2011). ERP system for effective management of co-operative sugar industries: A case study of Sahyadri SSK Ltd. International Journal of Information Technology and Knowledge Management, 4(1), 33-37.

Li, Y. R., \& Yang, L. T. (2015). Sugarcane Agriculture and Sugar Industry in China. Sugar Tech, 17(1), 1-8. doi:10.1007/s12355-014-0342-1

Masood, M. T., Khan, M. Z., \& Naqvi, H. (2011). Transportation Problems in Developing Countries Pakistan: A Case-in-Point. International Journal of Business and Management, 6(11), 256-266.

Mehta, P. (2018). RFID Technology in Supply Chains. India: Indian Institute of Technology Kanpur. Retrieved from http://home.iitk.ac.in/ pmehta/scmqip07/RFID\%20Technology\%20and\%20supply\%20chain.ppt

Ministry of Food Processing Industries, Government of India. (2005, April). Vision, strategy and action plan for food processing industries. Retrieved from http://mofpi.nic.in/images/volume1.pdf

Mishra, P. K. (2010). Bottlenecks in Indian food processing industry. FICCI Survey. Retrieved from http://www. ficci.com/SEDocument/20073/Food-Processing-Bottlenecks-study.pdf

Misra, R., Sinha, R., Kumar, R., Kumar, R., \& Richariya, N. (2011, February). The Fettered cold chain. Logistics Times, 1(10), 1-52. Retrieved from http://logisticsconsulting.asia

Perdana, Y. R. (2012). Logistics Information System for Supply Chain of Agricultural Commodity. Procedia: Social and Behavioral Sciences, 65, 608-613. doi:10.1016/j.sbspro.2012.11.172

Rahman, Z. (2003). Internet-based supply chain management: Using the internet to revolutionize your business. International Journal of Information Management, 23(6), 493-505. doi:10.1016/j.ijinfomgt.2003.09.004

Rahman, Z. (2004). Use of internet in supply chain management: A study of Indian companies. Industrial Management \& Data Systems, 104(1), 31-41. doi:10.1108/02635570410514070

Rao, N. H. (2007). A framework for implementing information and communication technologies in agricultural development in India. Technological Forecasting and Social Change, 74(4), 491-518. doi:10.1016/j. techfore.2006.02.002 
Salin, V., \& Jr Nayga, R. M. (2002). A cold chain network for food exports to developing countries. International Journal of Physical Distribution \& Logistics Management, 33(10), 918-933. doi:10.1108/09600030310508717

Singh, H. (n.d.). Challenges in operating integrated cold chain for horticulture: The journey of Fresh \& Healthy Enterprises Ltd (FHEL) [PowerPoint slides]. Retrieved from http://happytreeflash.com/harpreet-ppt.html

Sukyai, P., Yingkamhaeng, N., Lam, N., \& Sriroth, K. (2016). Research and Development Prospects for Sugarcane and Sugar Industry in Thailand. Sugar Tech, 18(6), 583-587. doi:10.1007/s12355-016-0495-1

Thaqi, A. Q. (2015). Integration of GIS \& GPS Systems on Vehicle Monitoring. In Proceedings of the 7th International Conference on Information and Communication Technologies in Agriculture, Food and Environment, Greece (17-20, September 2015).

The Hindu Business Line. (2007, December 5). India needs efficient cold chain soon: Godrej. Retrieved from www.thehindubusinessline.com

Toharisman, A. (2016). An Overview of Sugar Sector in Indonesia. Sugar Tech, 18(6), 636-641.

Vijayaraman, B. S., \& Osyk, B. A. (2006). An empirical study of RFID implementation in the warehousing industry. International Journal of Logistics Management, 17(1), 6-20. doi:10.1108/09574090610663400

Rupesh Kumar is presently working as an Assistant Professor at UPES, Dehradun. He also worked with SIOM, Nashik (Maharashtra), India. He worked as Post Doc Fellow at CEG-IST, Lisbon, Portugal. He is a recipient of Noel Deerr Gold Medal for the best paper presented during 72nd Convention of STAI. He worked with NGO Abhinav as Research Officer for more than two years and has industrial experience of more than one year. His $\mathrm{PhD}$ is from IIT Roorkee, India and MSc from Reading University, UK. His areas of interest are SCM, MCDA, and IT. He had participated in national/international conferences and published several papers and a book chapter in refereed journals. He did several projects in different countries like Greece, Spain, Portugal and the UK related to e-commerce, IT, networking, etc. 